\title{
27. Electron Microscopic Study of the Nerve Plexus in the Polyp of a Reef Coral*)
}

\author{
By Siro Kawaguti \\ Department of Biology, Faculty of Science, Okayama University \\ (Comm. by Yô K. OKADA, M.J.A., Feb. 12, 1964)
}

It is well known that the polyp of a reef coral is fairly sensitive to stimulus of various kinds. When the tip of a tentacle is given a slight touch with a forceps the tentacle contracts, and when the touch is moderately strong, not just the tentacle but the whole polyp reacts almost simultaneously. If the stimulus is strong enough a reaction appears even in the neighboring polyps. The problem how the stimulus is propagated to the whole of the polyp and also to the neighboring polyps is very interesting.

Since the classical work of the Hertwigs, ${ }^{2)}$ the coelenterates have been believed to have a nervous network under the epidermal layer. The network is constructed of many ganglion cells which have long branches and are scattered throughout the body. These branches make contacts with those of neighboring cells forming a network connection of nervous cells. Thus the network pattern of the nervous system of the sea-anemones or the coelenterates in general has been a common figure in a textbook of zoology. ${ }^{37}$ Recent work by Batham, Pantin and Robson ${ }^{12}$ also has demonstrated a network distribution of nerve cells in a sea-anemone, Metridium senile.

Electron microscopic study on the structure of zooxanthellae in a reef coral $^{6)}$ gave a chance to the author to observe structures of the nerve plexus in this animal. The nerve plexus is not observed as a network structure but is composed of a thick layer of nerve fibers just outside the ectodermal muscle layer.

The coral used in this experiment was Oulastrea crispata which was collected from the vicinity of the Tamano Marine Laboratory of Okayama University. This coral expands its polyps in the daytime. ${ }^{5)}$ Each polyp measures variously from $4 \mathrm{~mm}$ to $8 \mathrm{~mm}$ in the diameter of its oral disc. The polyp as a whole has a brown color owing to the presence of zooxanthellae in its endoderm. But the oral disc and the upper surface of the tentacles show a green color, especially when they are expanded in a bright light because these portions are ornamented with an ectodermal green fluorescent pigment.") The green pigment in ectodermal cells is found in small spherical

\footnotetext{
*) Contribution from Tamano Marine Laboratory, No. 109.
} 


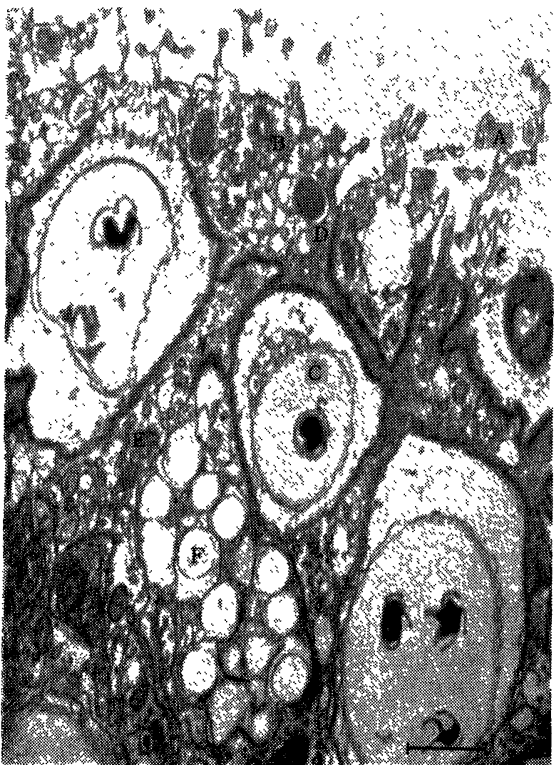

Fig. 1. Low power electron micrograph of the surface portion of the ectoderm of the coral polyp. $\times 8,000$

A: palisade, B: mucous granules, C: nematocysts, D: desmosome, E: vesicles; F: pigment granules.

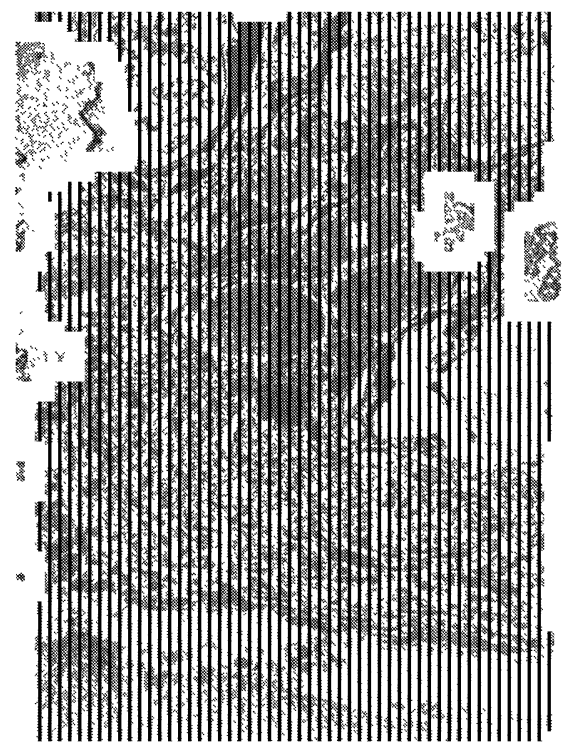

Fig. 2. A proximal portion of the ectoderm of the coral polyp showing a nerve plexus $(\mathrm{P})$, muscle fibers $(\mathrm{S})$, and the mesogloea $(G)$ in the lower portion. $\times 5,000 \mathrm{~N}$ : nucleus.

bodies (Fig. 1).

Samples for an electron microscopic study were dissected from the oral disc after narcotization of the animal with magnesium sulphate or without treatment. The cut samples were fixed in $1 \%$ osmium tetroxide with buffered sea water for 1 hour. They were dehydrated in a series of alcohols and embedded in epon. The sections were cut on a glass knife and stained with potassium permanganate.

Fig. 1 is a low power electron micrograph of a somewhat oblique section through the surface portion of the ectoderm. The upper surface is provided with palisades and cilia. The ectodermal cells are slender and contain small vesicles, mucous granules, small mitochondria and comparatively large nuclei (Fig. 2). Each cell shows close connections with the neighboring ones by means of desmosomal structures. Among these cells there are also nematocysts, mucous cells and chromatophores each of which shows characteristic features as will be seen in the figures. A detailed description of these cells will have to be given in separate papers. The proximal surface of the ectodermal layer is lined with the mesogloea (Fig. 2). The mesogloea is a thick layer of rather homogeneous structure. However, further magnification reveals that this layer is composed of thin 
threads which run in various ways and bear obscure bands of about $200 \mathrm{~A}$ in width.

The dark patches above the mesogloea are somewhat oblique cut surfaces of the muscle fibers. These fibers have no sign of regular distribution in their myofilaments and so they belong to smooth muscles. These cells have mitochondria and small vesicular bodies in their peripheral portions which frequently show many processes, especially through to the opposite side of the mesogloea. These processes are submerged into a thick layer of nerve plexus. The structure of the muscle fibers shows a far more undeveloped state than those of the muscles of the velum of an anthomedusa, Spirocodon saltatrix. ${ }^{8)}$

The main portion of the nerve plexus in Fig. 2 is enlarged in Fig. 3. The portion is composed of vesicular bodies of various shapes and dimensions which are sections of nerve fibers cut on different planes. Some are nearly longitudinal and some others are cross sections showing circular or oval forms. These nerve fibers have thick plasma membranes and contain small vesicles which may be considered to be synaptic vesicles. Besides these vesicles, there are large vesicles of $1,000 \mathrm{~A}$ in diameter which contain many dense particles. These large vesicles are also one of the characteristic components in the nerve fibers. Some nerve fibers, especially the larger ones, contain

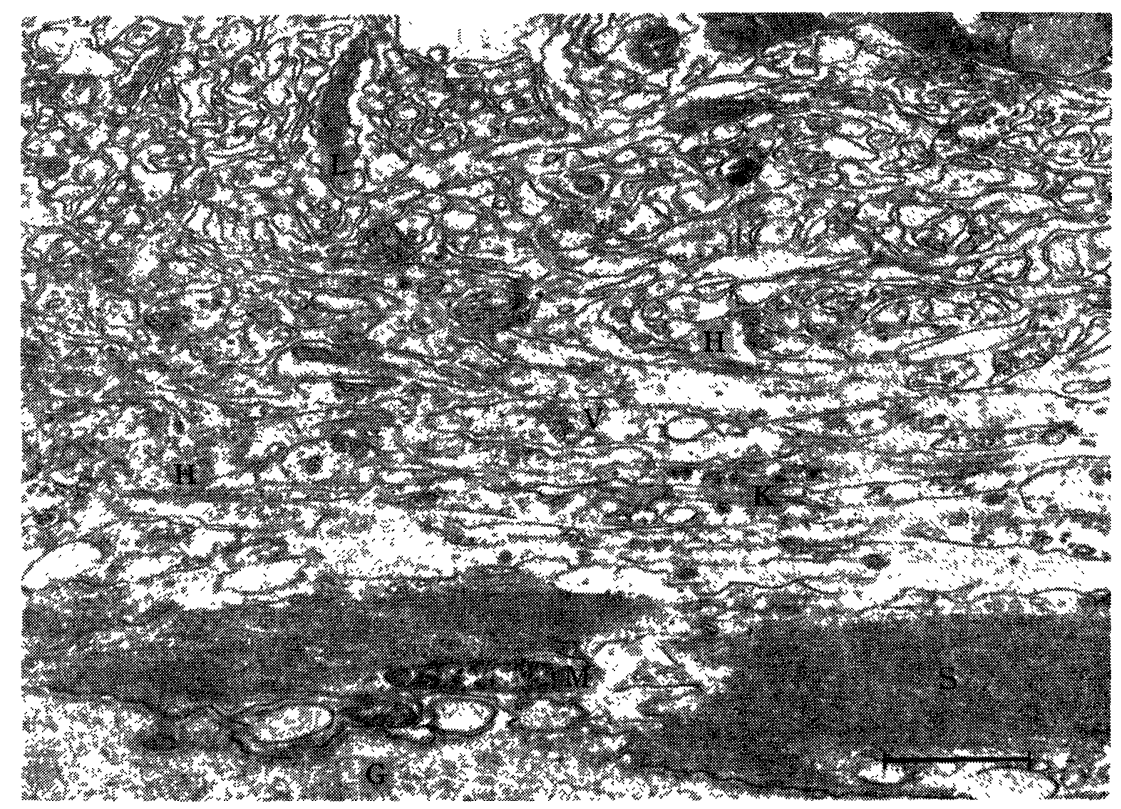

Fig. 3. Magnification of the nerve plexus of the coral polyp, $\times 15,000$. M: mitochondria, $\mathrm{V}$ : synaptic vesicles, $\mathrm{H}$ : desmosome between nerve fibers, $\mathrm{K}$ : large vesicles, L: neurofilaments. 
fibrous elements which correspond to neurofilaments in those of the vertebrates, molluses and arthropods.

As is clear in the figures, the nerve fibers run close together in various directions but mainly along the longitudinal axis of the polyp, forming: a thick coating of more than 10 layers of fibers. These fibers frequently show synaptic structures between neighboring ones. These facts demonstrate complicated connections among the nerve fibers in the nerve plexus, which are far too complicated to be called a network.

The results thus obtained should be compared with those of the sea-anemone, Anthopleura, ${ }^{11)}$ those of gorgonians, Euplexaura ${ }^{7)}$ and Anthoplexaura, and those of an anthomedusa, Spirocodon saltatrix. ${ }^{8}$ The Spirocodon shows no such nerve plexus. Gorgonians have a rather simple nerve plexus. The nerve plexus of the sea-anemone exhibits practically identical structures with those of the reef coral. Moreover, it is very interesting to note that the nerve plexus in the tube foot wall ${ }^{10)}$ and in the body integument ${ }^{9)}$ of some echinoids afford similar pictures in the electron micrographs.

Why have light microscopic workers only mentioned simple network structures for the nervous system of the coeleterates? These fine structures mentioned above are very small and contain few elements that can be stained well for light microscope observation. The only exception may be neurofilaments which are few in number and may be observed as network branches of the nerve cells. The rest of the nerve fibers in the plexus have been concealed beyond the limit of the light microscope.

\section{References}

1) Batham, E. J., C. F. A. Pantin, and E. A. Robson (1960): Q. J. M. S., 101, 487-510.

2) Hertwig, O., and R. Hertwig (1877): Jena. Zeit. Naturw. 11.

3) Hyman, L. H. (1940): The invertebrates. I. McGraw-Hill, New York.

4) Kawaguti, S. (1944): Palao Trop. Biol. Stat. Studies, 2, 617-673.

5) _- (1954): Biol. Jour. Okayama Univ., 2, 45-50.

6) - (1964): Ibid., 10 (in press).

7) - (1964): Ibid., 10 (in press).

8) Kawaguti, S., and T. Hamakoshi (1963): Ibid., 9 (3-4).

9) Kawaguti, S., and Y. Kamishima (1964): Annot. Zool. Japon., 37 (in press).

10) Kawaguti, S., and N. Ikemoto: Unpublished.

11) - : Unpublished. 